\title{
8
}

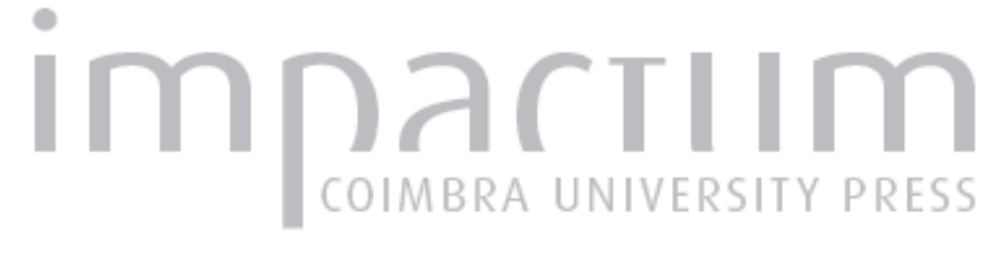

\section{A violência em Portugal na Idade Moderna: olhares historiográficos e perspectivas de análise}

Autor(es): Neto, Margarida Sobral

Publicado por: Instituto de História Económica e Social; Imprensa da Universidade de

URL

persistente:

URI:http://hdl.handle.net/10316.2/44493

DOI: $\quad$ DOl:https://doi.org/10.14195/0870-4147_37_1

Accessed : $\quad$ 26-Apr-2023 13:59:07

A navegação consulta e descarregamento dos títulos inseridos nas Bibliotecas Digitais UC Digitalis, UC Pombalina e UC Impactum, pressupõem a aceitação plena e sem reservas dos Termos e Condições de Uso destas Bibliotecas Digitais, disponíveis em https://digitalis.uc.pt/pt-pt/termos.

Conforme exposto nos referidos Termos e Condições de Uso, o descarregamento de títulos de acesso restrito requer uma licença válida de autorização devendo o utilizador aceder ao(s) documento(s) a partir de um endereço de IP da instituição detentora da supramencionada licença.

Ao utilizador é apenas permitido o descarregamento para uso pessoal, pelo que o emprego do(s) título(s) descarregado(s) para outro fim, designadamente comercial, carece de autorização do respetivo autor ou editor da obra.

Na medida em que todas as obras da UC Digitalis se encontram protegidas pelo Código do Direito de Autor e Direitos Conexos e demais legislação aplicável, toda a cópia, parcial ou total, deste documento, nos casos em que é legalmente admitida, deverá conter ou fazer-se acompanhar por este aviso. 


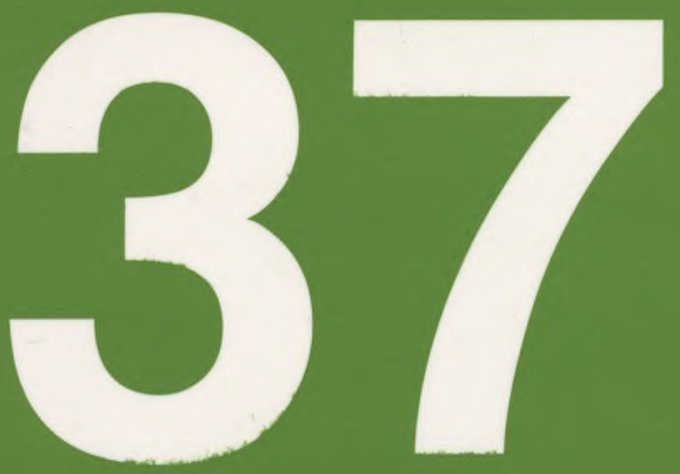

Revista Portuguesa de História

Faculdade de Letras da Universidade de Coimbra Instituto de Historia Econónica e Samial

Coimbra 05 
Revista Portuguesa de Historia

t. XXXVII (2005)

pp. $9-27$

\section{A Violência em Portugal na Idade Moderna: olhares historiográficos e perspectivas de análise}

MARgarida Sobral Neto*

Faculdade de Letras da Universidade de Coimbra

«Do rio que tudo arrasta se diz que é violento; mas ninguém diz violentas as margens que o comprimem»"

Berthold Brecht

\section{1. À procura da definição de um conceito}

"A violência não é una mas múltipla. Movediça, muitas vezes inatingível, sempre a transformar-se, ela designa - conforme os lugares, as épocas, as circunstâncias, ou os lugares - realidades muito diferentes"1. Violência é, na sociedade actual, uma palavra de uso quotidiano, sendo o seu conteúdo semântico muito

Professora associada da Faculdade de Letras da Universidade de Coimbra. Membro do Centro de História da Sociedade e da Cultura. Cumpre-nos agradecer a leitura crítica que deste texto foi feita pela Doutora Maria Antonia Figueiredo Lopes e pela mestre Dina Alves.

${ }^{1}$ CHESNAIS, Jean-Claude, Histoire de la violence en Occident de 1800 à nos jours, Paris, Robbert Laffont, 1981, p. 11. 
amplo. As utilizações do vocábulo reflectem a "reactividade aversiva" (Elias)2 a múltiplos usos da força, material ou simbólica, que se diversificam no contexto de uma sociedade globalizada ${ }^{3}$. Esta representação da violência gera sentimentos de medo e de desprotecção propícios à implantação de diversos mecanismos de segurança susceptíveis de envolverem em si mesmos formas de violência física e sobretudo simbólica 4 .

A violência não é um fenómeno específico da nossa sociedade. É uma componente do viver social que tem assumido expressões diversas ao longo do tempo, sendo igualmente diversas as estratégias utilizadas pela sociedade para lidar com este fenómeno. Acreditamos que olhando a violência na espessura do tempo, na longa duração (Braudel), seremos capazes de analisar de forma mais adequada as suas expressões actuais, as visíveis e sobretudo as invisíveis, contribuindo para que se encontrem os meios mais consentâneos à construção da paz no seio das sociedades e no concerto das nações.

Propomo-nos abordar neste texto algumas das representações do fenómeno da violência na Idade Moderna que nos têm sido transmitidas pela recente historiografia. Cumpre-nos iniciar a abordagem desta problemática com algumas reflexões sobre o conceito de violência". A palavra "violencia" era usada na Idade Moderna tendo Rafael Bluteau registado, no seu Vocabulario as seguintes ocorrências dos termos violência e violento: "vento violento", "violencia do frio", "violencia das doenças", "violento, vehemente, impetuoso, fallando em vento, tormenta, torrente, ira, ou outra payxão furiosa", "homem violento, arrebatado, que facilmente se deixa levar da ira", "violento, não natural", "morrer de morte violenta, he morrer não de doença, ou de velhice, mas de feridas, ou outras violências ou desgraças", "por mãos violentas em alguém. He frase das censuras

2 Sobre este conceito ver ELIAS, Norbert, Processo civilizacional, Lisboa, Publicações Dom Quixote, 1999.

3 ENGELHARD, Philippe, La violence de l'Histoire, Paris, Arléa, 2001.

4 CASTEL, Robert, L 'insécurité sociale, Éditions du Seuil e La République des Idées, 2003.

5 Sobre o conceito de violência ver: CHESNAIS, Jean-Claude, Histoire de la violence en Occident de 1800 à nos jours; ARENDT, Hannah, Da violência, trad. de Maria Claudia Drummond Trindade, Brasília, Editora Universidade de Brasilia, 1985; MICHAUD, Yves La violence, Paris, Presses Universitaires de France, 1992; S. Giora Shoham e outros, Violence: an integrated multivariate study of human aggression, Aldershot, Dartmouth, 1995; GIRARD, René, La violence et le sacré, Paris, Hachette/Pluriel, 1994. A psicologia social prefere a utilização do conceito de agressão ao de violência. Sobre este conceito, bem como sobre as teorias explicativas da agressão Cf. FISCHER, Gustave-Nicholas, A dinâmica social. Violência, Poder e Mudança. Lisboa, Planeta Editora, 1994, pp. 31-68; LORENZ, Konrad, A agressão. Uma História Natural do Mal. Lisboa, Relógio d'Água, 1992. 
Ecclesiasticas, val o mesmo que ferir ou matar", "eu fui violentado a fazer isto"'. De acordo com as definições de Bluteau o homem, ou a natureza, passavam do estado natural ao estado violento ("violento, não natural"), do equilíbrio ao desequilíbrio, quando eram movidos por uma força excessiva geradora de fenómenos naturais (vento, frio, tormenta) ou sentimentos (paixão furiosa, ira) fortes e excessivos. Os sentidos da palavra atrás enunciados comportam ainda os conceitos de agressão física "por mãos violentas em alguém" e de coacção psicológica "fui violentado a fazer isto", sentidos que perduram no tempo.

Violência pode, assim, significar agressão física, contra alguém (sendo esta uma dimensão objectiva e mensurável) ou coacção psicológica. A violência contra o Outro pode expressar-se ainda de forma indirecta, através da agressão aos bens, percepcionados, simbolicamente, como uma extensão do próprio corpo $^{7}$. Neste contexto consideramos operatória, para a análise da violência na Idade moderna, a definição de Yves Michaud: "Há violência quando numa situação de interacção, um ou vários actores agem de maneira directa ou indirecta, de forma concentrada ou repartida, atingindo uma ou várias pessoas, em graus variáveis, na sua integridade física ou na sua integridade moral, nos seus bens ou nas suas representações simbólicas e culturais"8.

A classificação de um acto como violento depende do contexto em que ele ocorre bem como da sua proveniência. Como afirma Gustave-Nicolas Fisher "os problemas da violência estão ligados a representações sociais que os codificam positiva ou negativamente, segundo o tipo admitido ou recusado pelas categorias em presença", dependendo a diferente conotação e valoração da atitude violenta do facto de se considerar que ela promove a ordem ou a desordem ${ }^{9}$.

\section{A violência como objecto historiográfico}

Os historiadores sempre dedicaram uma particular atenção ao estudo da guerra, uma das formas mais brutais e organizadas da violência ${ }^{10}$. A perspectiva de análise deste fenómeno situou-se, no entanto, durante longo tempo, na área

6 Rafael Bluteau, Vocabulário Portuguez \& Latino, Lisboa Ocidental, Na Officina de Pascoal da Sylva, 1721.

7 MUCHEMBLED, Robert, La violence au village. Sociabilité et comportements populaires en Artois du XVau XVIII siècle. Brepols, 1989, pp. 144-160.

8 Y. Michaud, Yves Michaud, La violence, Paris, PUF, 1986.

9 FISCHER, Gustave-Nicholas, A dinâmica social..., p. 15.

10 "A história dos homens e das mulheres regorgita de guerras: é mesmo (talvez), no longo prazo, mais uma história das guerras e dos confrontos do que uma história das concórdias e dos tratados de paz" (Arlette Farge, "Da guerra", in Lugares para a História, Teorema, 1999). 
da história política e diplomática, num registo de estudo de acontecimentos e protagonismos heroicos de figuras políticas e militares, donde estavam, por norma, ausentes as dimensões da violência e do sofrimento humano". Marc Bloch, uma das vítimas da segunda guerra mundial, considerou a conflito bélico como uma fonte de conhecimento para o historiador ${ }^{12}$. As opções historiográficas deste autor, bem como a de outros que viveram a amarga experiência do teatro da guerra, demarcaram-se, porém, radicalmente de uma história tradicional, pejorativamente classificada como "histoire bataille", para seguir os novos caminhos da história económica e social. O estudo do conflito bélico viria a ser recuperado em França, na década de setenta, tendo os historiadores modernistas, em 1979, escolhido como tema do seu colóquio anual "a guerra na Idade Moderna", retomando-se, a partir daí, a investigação sobre este assunto, em diversas perspectivas incluindo a da violência ${ }^{13}$. Em Portugal, os frutos de uma investigação renovada em história da guerra estão presentes na "Nova História Militar" de Portugal, dirigida por Nuno Severiano Teixeira e Manuel Themudo Barata. José Mattoso, na introdução ao primeiro volume que coordenou, apresenta uma perspectiva muito alargada e actual de abordagem da guerra, destacando-se a visão antropológica. Partindo do pressuposto de que a "violência constitui uma das formas mais omnipresentes e mais perturbadoras da existência humana" afirma este autor que a Nova História Militar "quereria ser também um grito de esperança na capacidade humana para transformar os seus instintos destruidores em energia construtiva"14.

No volume referente à Idade Moderna, coordenado por António Hespanha a guerra é abordada em diversas perspectivas (imaginário e deontologia, técnicas e tácticas, formas de recrutamento, relações existentes entre a guerra, a sociedade e o sistema de poder), espaços (continental, insular, norte de África, índia e Brasil)

11 Sobre a historiografia da guerra, bem como sobre as concepções de guerra na Idade Moderna ver Rui Bebiano, A pena de Marte. Escrita da guerra em Portugal e na Europa (séculos XVI-XVIII), Coimbra, Edições Minerva Coimbra, 2000.

12 “ La guerre, je l'ai dit plus haut, a été une immense expérience de psycologie sociale. Se consoler de ses horreurs en se félicitant de son intérêt experimentale serait affecter un dilettantisme de mauvais ton. Mais, puisqu'elle a eu lieu, il convient d'employer ses enseignements, au mieux de notre science. Hâtons-nous de mettre a profit une occasion, qu il faut espérer unique" (BLOCH, Marc, "Réflexions d'un historien sur les fausses nouvelles de la guerre", in Histoire et Historiens, Paris, Armand Colin, p. 166).

13 Sobre perspectivas de abordagem da guerra ver : CONTAMINE, " L'Histoire militaire ", in BÉDARIDA, François (dir), L Histoire et le métier d'historien en France 1945-1995, Paris, Maison des sciences de l'homme, 1995,359-367 ; AUDOIN-ROUZEAY, Stéphane, La violence de guerre: 1914-1945: approches comparées des deux conflits mondiaux, Bruxelles, Complexe, 2002.

14 TEIXEIRA, Nuno Severiano e BARATA, Manuel Themudo (dir), Nova História Militar de Portugal, Lisboa, Círculo de Leitores, vol. I, p. 19. 
e conjunturas (guerra da Restauração e Sucessão de Espanha) ${ }^{15}$. A História da guerra na Idade Moderna prossegue no terceiro volume da "Nova História Militar", coordenado por Manuel Themudo Barata, com a análise da Guerra das Laranjas e Invasões Francesas ${ }^{16}$.

Um dos principais caminhos para o estudo das acções violentas, no passado, tem sido o crime, assumindo-se, a história da criminalidade como uma das partes mais consistentes da história da violência ${ }^{17}$. Um marco decisivo neste caminho historiográfico foi a criação, em 1978, da International Fondation for the History of Crime and Criminal Justice que congregou os historiadores de direito penal e muitos outros que se dedicavam ao estudo dos comportamentos, campo para onde convergiam a demografia histórica, a história social, cultural, das mentalidades e da vida quotidiana.

Em França, iniciaram-se, na década de setenta, pesquisas sistemáticas sobre o fenómeno da criminalidade incidindo sobre áreas geográficas específicas: Chaunu impulsionou estudos sobre a Normandia, Yves Castan e Nicole Castan sobre o Languedoc ${ }^{18}$; Malcolm Greenshields sobre a região de Haute Auvergne ${ }^{19}$ e Robert Muchembled sobre o Artois ${ }^{20}$. Por sua vez Arlette Farge e André Zysberg dedicaram-se ao estudo da sociabilidade das ruas de Paris ${ }^{21}$.

15 TEIXEIRA, Nuno Severiano e BARATA, Manuel Themudo (dir), Nova História Militar de Portugal, Lisboa, Círculo de Leitores, 2003, vol. IL

16 TEIXEIRA, Nuno Severiano e BARATA, Manuel Themudo (dir), Nova História Militar de Portugal, Lisboa, Círculo de Leitores, 2003, vol. III.

17 IGLESIAS ESTEPA, "El crimen como objecto de investigación historica », Obradoiro de Historia Moderna, $\mathrm{n}^{\circ} 14$, 297-318, 2005, pp. 289-318 ; ABBIATECI, F. Billacois, Y. Castan, P. Petrovich, Y Bongert, N. Castan, Crimes et criminalité en France 17e-18e siècles, Cahiers des annales, 33, Paris, Armand Colin, 1971 ; STONE, Lawrence, Interpersonal violence in English society. 1300-1980, Past and Présent, $\mathrm{n}^{\circ}$ 101, november, 1983, pp. 22-33.

18 CASTAN, Yves, "Mentalités rurale et urbaine à la fin de l'Ancien Régime dans le ressort du Parlement de Toulouse d'après les sacs à procès criminels ( 1730-1790) ", in Crimes et criminalité en France 17-18 siècles, Cahiers des Annales, Paris, 1971, pp. 109-165; CASTAN, Yves, Vivre ensemble - ordre et désordre en Languedoc (XVII - XVIII siècles), Paris, Gallimard, 1981; CASTAN, Nicole, Justice et répression en Languedoc à l'époque des lumières, Paris, Fammarion, 1980; CASTAN, Nicole, Les criminels du languedoc. L 'exigence d 'ordre et les voies de ressentiment dans une sociétépré-revolutionnaire (1750-1790), Université de Toulouse le Mirail, 1980.

19 CAMERON, Iain, Crime and repression in the Auvergne and the Guyenne, 1720-1790, Cambridge, 1981 ; GREENSHILDS, Malcolm, An economy of violence in Early Modem Fance. Crime and Justice in the Haute Auvergne, 1587-1664. The Pennsylvania State University Press, s.d.

20 MUCHEMBLED, Robert, La violence au village. Sociabilité et comportements populaires en Artois du XVau XVIII siècle. Brepols, 1989.

21 FARGE, Arlette; ZYSBERG, André, "Les théâtres de la violence à Paris au XVIIIème siècle", Annales E.S.C., 34 année, Septembre-Octobre 1979, pp. 984-1015 ; FARGE, Arlette, La vie fragile. Violence, pouvoirs et solidarités à Paris au XVIIIe siècle, Hachette, 1986. 
O estudo dos comportamentos violentos alicerçou-se na exploração sistemática de arquivos judiciais ${ }^{22}$, sendo os dados "extraídos" dessas fontes tratados com base numa metodologia serial, na chamada "história quantitativa de terceiro nível". Devido, entre outros factores, à natureza das próprias fontes o fenómeno da violência analisou-se em estreita articulação com o processo de modelação e criminalização dos comportamentos operado na Idade Moderna, fenómeno em que se envolveram diversas instâncias de controlo e repressão social ${ }^{23}$. A história da violência surge deste modo intrinsecamente ligada a uma nova história do poder (Foucault) ${ }^{24}$, ou dos poderes, assumindo-se, de forma incontornável, o seu objecto de estudo como um "facto social total" (Mauss). Esta abordagem implicou, por sua vez, um diálogo interdisciplinar entre a História, o Direito, a Sociologia, a Antropologia e a Biologia.

Em Portugal, os estudos sobre violência e criminalidade iniciaram-se nos finais da década de setenta tendo sido pioneiro o artigo de João Lourenço Roque sobre a criminalidade no distrito de Coimbra nos anos de 1841 a $1844^{25}$. Dez anos depois, publicava-se o estudo de João Fatela sobre a criminalidade portuguesa entre 1926 e 1946, trabalho elaborado num registo antropológico ${ }^{26}$.

$\mathrm{Na}$ década de oitenta a violência e a criminalidade constitui-se como tema de pesquisa para dissertações de doutoramento, tanto na área da História Contemporânea como na da História da Idade Média, sendo expressão desta escolha as teses de Irene Vaquinhas ${ }^{27}$ e de Luís Miguel Duarte28. Às teses de

22 Sobre as potencialidades e limitações das fontes judiciais, bem como sobre os problemas que se colocam ao seu aproveitamento ver: FARGE, Arlette, Le Goût de l'archive, Seuil, coll. "Librairie du XX éme siècle, 1989; IGLESIAS ESTEPA, «El crimen como objecto de investigación historica», Obradoiro de Historia Moderna, n 14, 297-318, 2005, pp. 313-318.

23 Sobre o processo de modelação de comportamentos operado na Idade Moderna ver: Norbert Elias, O processo civilizacional. Lisboa, Dom Quixote, 1989, 2 vols; Robert Muchembled, L 'invention de 1 'homme moderne. Sensibilités, moeurs et comportements collectifs sous 1 'Ancien Régime, Paris, Fayard, 1988.

24 FOUCAULT, Michel, Microfisica do poder, 13. ed., Rio de Janeiro, Edições Graal, 1998, Idem, Surveiller et punir: naissance de la prison, Paris, Gallimard, 1982.

25 ROQUE, João Lourenço, Alguns aspectos da criminalidade no distrito de Coimbra nos anos de 1841 a 1844. "Boletim do Arquivo da Universidade de Coimbra", vol. III, Coimbra, 1978.

26 FATELA, João, O sangue e a rua. Elementos para uma antropologia da violência em Portugal (1926-1946), Lisboa, Dom Quixote, 1989.

27 VAQUINHAS, Irene, Notas para a história da violência rural, em Portugal, na segunda metade do século XIX. "Revista Portuguesa de História", t. XXVII, Coimbra, 1992; VAQUINHAS, Irene, Violência, Justiça e Sociedade Rural: os campos de Coimbra, Montemor-o- Velho e Penacova de 1858 a 1918, Porto, Afrontamento, 1997.

28 DUARTE, Luís Miguel, Justiça e Criminalidade no Portugal Medievo (1459-1481), Lisboa, Fundação Calouste Gulbenkian, Fundação para a Ciência e Tecnologia, Ministério da Ciência e da Tecnologia, 1999. 
doutoramento seguiram-se as de mestrado, algumas delas na área da História Moderna, realizadas em Coimbra ${ }^{29}$. Entretanto, a riqueza da documentação de natureza judicial, bem como outra que nos permite entrever comportamentos violentos, foi seduzindo os historiadores, feliz encontro de que têm resultado vários e interessantes estudos publicados em $\operatorname{livros}^{30}$ e revistas ${ }^{31}$.

\section{A violência do quotidiano}

Quando projectamos o nosso olhar sobre as sociedades dos séculos XV ao XVIII identificamos múltiplas expressões da violência que se configuram diferentemente em função dos espaços (urbanos e rurais) e das conjunturas temporais, protagonizadas por homens "violentos" dotados de força física, treinada nos rituais juvenis da aprendizagem da vida e consolidada no trabalho duro de remover a terra, que produzia o pão ou as pedras que erguiam catedrais, num tempo em que uma das principais fontes de energia era a humana. Homens violentos encontramo-los igualmente nos grupos sociais mais elevados que canalizavam a sua energia nas artes da guerra, nos duelos ou nas brigas em que, com frequência, desembainhavam espadas ou manejavam armas de fogo. Muito insubmissos, "selvagens" e "rústicos", eram ainda os desenraizados, os vagabundos e ciganos, que procuravam o seu sustento nos campos e nos caminhos íngremes e pedregosos através de roubos de produtos agrícolas ou de assaltos aos viandantes.

Estes homens, mesmo os mais fortes, tinham vidas frágeis, marcadas por curtas esperanças de vida, ceifada pela fome, pelas doenças ou por agressões violentas (infanticídios, homicídios, ataques de animais ferozes ou penas de

29 RAMOS, Anabela, Violência e justiça em terras de Montemuro. 1708-1820, Viseu, Palimage Editores, 1998; ALVES, Dina Catarina Duarte, Violência eperdão em Óbidos (1595-1680), Coimbra, Fac. Letras, 2003, tese de mestrado policopiada.

30 VAZ, Maria João, Crime e Sociedade, Portugal na segunda metade do século XLY, Oeiras, Celta, 1998.

31 MONTEIRO, Isilda Braga da Costa Monteiro, “A litigiosidade e o " perdão» em Vila Nova de Gaia (séculos XVII e XVIII)", Revista de ciências históricas, vol. XI, Universidade Portucalense, Porto; COSME, João dos Santos Ramalho, Cartas de perdão concedidas a açorianos (1642-1748), "Boletim do Instituto Histórico da Ilha Terceira", Angra do Heroísmo, 1990, vol. 48, pp. 317-348; BRAGA, Isabel M. R. Mendes Drumond, A criminalidade em Portalegre no reinado de D. João III: delitos e perdões. "A Cidade", Nova série, Portalegre, 1993 (8), pp. 65-81; RODRIGUES, José Damião Rodrigues, Criminalidade e violência em Ponta Delgada no final do Antigo Regime (1706-1817). Para uma outra leitura das relações sociais, Ponta Delgada, 1999. 
mortes). Neste contexto, a visão da morte fazia parte do quotidiano, coabitando com os homens nas casas, nas ruas, nas forcas, nos patíbulos ou nos autos de fé que impregnavam o ar de cheiro de morte. A convivência íntima com os momentos de passagem da vida terrena para o Além manifestava-se na morte assistida; em casa por familiares e amigos, nos espaços públicos por toda a comunidade que se irmanava por laços familiares, de parentesco ou de interconhecimento, parecendo, por vezes, desfrutar do brutal espectáculo do sofrimento. Os crentes conviviam ainda com os símbolos da morte nos locais de culto religioso, presentes em pinturas, nas imagens de Cristo cruxifícado e nos sermões impregnados de ideias de purgatório e inferno, veículos de uma mensagem culpabilizante e construtora do medo ${ }^{32}$. Inferno que, em muitos casos era terreno, como o vivido pelas crianças expostas, arrancadas ao colo materno por razões económicas ou do foro moral ${ }^{33}$.

\section{Relações interpessoais criminalizadas}

Constituindo a violência parte integrante do quotidiano das relações humanas e da sociabilidade de diversos grupos da população, bem como dos mecanismos de dominação dos poderes, este fenómeno pode estudar-se a partir de várias fontes. Em Portugal, como noutros países, o observatório privilegiado da violência começou por ser os registos produzidos pelo aparelho judiciário cuja função era repor a ordem quebrada pelo "criminoso" ou "criminosos", através dos mecanismos da punição ou do perdão.

Quando um perturbador da ordem estabelecida era apanhado nas malhas da justiça podia dirigir-se ao rei e implorar o perdão. A concessão de perdão pelo monarca pressupunha a obtenção, por parte do agressor, do perdão da vítima ou dos seus familiares, no caso de aquela ter falecido, acto que tinha de assumir a formalidade de registo escrito nas notas do tabelião. Perdões da parte e régios, documentos susceptíveis de aproveitamento serial, apesar das suas limitações ${ }^{34}$

32 DELUMEAU, Jean, La peur en Occident, XlVe-XVllle siècles: une cité assiégée, Paris, Fayard, 1978.

33 Entre a vasta bibliografia sobre crianças expostas destacamos as seguintes obras: LOPES, Maria Antonia, Pobreza, Assistência e Controlo Social, Viseu, Palimage, 2000,2 vols; SÁ, Isabel Cristina dos Guimarães Sanches e A circulação de crianças na Europa do Sul: o caso dos expostos do Porto no século XVIII, Lisboa, Fundação Calouste Gulbenkian, Junta Nacional de Investigação Científica e Tecnológica, 1995.

${ }^{34}$ Como afirma Robert Muchembled as cartas de perdão "não merecem nem confiança excessiva nem desconfiança sistemática” (¿a Violence au Village, pp. 17-18). 
assumem-se como uma das fontes a partir das quais tem sido possível estudar as tendências e os tipos da criminalidade registadas numa época e numa região ${ }^{35}$.

Para além do perdão da parte ou régio, outras fontes têm sido aproveitadas para o estudo da violência, destacando-se as querelas ${ }^{36}$ e as devassas ${ }^{37}$. A documentação produzida no contexto de querelas e devassas, nomeadamente os livros de "autos de querela", "sumários de querelas", "rol de culpados" e "baixas de culpados", cruzados com perdões régios e perdões da parte têm constituído a matéria-prima para a elaboração de alguns estudos de incidência regional ou local.

Ao nível do concelho, primeira instância judicial de controlo de "desordens", produziam-se ainda outros registos indicativos da violência quotidiana, tanto da que emergia no seio das comunidades como daquela que se abatia sobre elas proveniente de diversas sedes de poder, como eram as correições efectuadas pelas câmaras ou pelos corregedores ${ }^{38}$.

Das instâncias inferiores, os processos crimes passavam em seguida para a alçada dos corregedores, sendo posteriormente canalizados para os tribunais da Relação do Porto ou Suplicação de Lisboa, núcleos documentais que se

35 Entre os estudos elaborados com base em perdões régios destacamos os seguintes: COSME, João, "Cartas de perdão concedidas a açorianos (1642-1748/', in Boletim do Instituto Histórico da Ilha Terceira, Angra do Heroísmo, 1990, vol. 48, pp. 317-348. COSME, João, "Cartas de perdão e legitimação concedidas aos moradores do Arquipélago da Madeira: (1531-1557)", Região Autónoma da Madeira, Sec. Regional do Turismo, Cultura e Emigração, Centro de Estudos de História do Atlântico, sep. de Actas do II Colóquio Internacional de História da Madeira, Funchal, Set. 1989; VIEIRA, Aires dos Passos, "Subsídios para a história da criminalidade da Madeira nas épocas de Filipe II e III", in Actas do III Colóquio internacional de História da Madeira, Região Autónoma da Madeira, Madeira, 1993, pp. 473-490; BRAGA, Isabel M. R. Mendes Drumond, "A criminalidade em Portalegre no reinado de D. João III: delitos eperdões ", A Cidade, Nova série, Portalegre, 1993 (8), pp. 65-81.

36 Querela era "a delação que alguém faz em juízo competente de algum facto criminoso por interesse particular e público". (PEREIRA E SOUSA, Joaquim José Caetano, Esboço de um dicionário jurídico, Lisboa, 1825, t.3, voc. querela).

37 A devassa era um "acto jurídico pelo qual se inquiriam testemunhas para informação de algum crime, versava sobre delitos incertos, ou já conhecidos mas ignorando-se o agressor" (Anabela Ramos). A devassa podia ser geral, a que se realizava nos meses de Janeiro para uns crimes e nos de Junho e Agosto para outros, inserindo-se numa rotina de controlo social a que eram obrigados os juízes ordinários, ou especial quando visava um crime específico. Sobre as potencialidades e limitações de querelas e devassas para o estudo da violência, bem como a respectiva crítica ver RAMOS, Anabela Ramos, Violência e Justiça, cit., pp. 32-38.

38 CAPELA, José Viriato, Política de Corregedores. A actuação dos corregedores nos municípios minhotos no apogeu e crise do Antigo Regime (1750-1834), Braga, Universidade do Minho, 1997; Idem, O concelho de Guimarães nos capítulos de correição dos séculos XVIII e XIX (1752-1831), in Revista de Guimarães, n 103, 1993, pp. 225-296. 
revestirão de enorme importância para o historiador a partir do momento em que se criarem as condições para aceder a esses arquivos.

Perdões da parte e régios, querelas e devassas revelam-nos uma sociabilidade violenta expressa sobretudo em agressões físicas, que por vezes resultavam em mortes, e agressões à honra e dignidade materializadas em injúrias ou, numa escala mais grave, em crimes sexuais. A principal vítima deste tipo de violência era a mulher, projectando-se, no entanto, a desonra sobre toda a família, facto que, por sua vez, motivava uma reparação igualmente violenta ${ }^{39}$.

As ofensas corporais ocorriam em contextos de sociabilidade muito intensa propícios a explosões de agressividade não reprimida por processos de interiorização de normas sociais e de autocoacção ${ }^{40}$. Os palcos de conflitos geradores de agressões eram as tabernas, os trabalhos agrícolas e artesanais, os divertimentos e as festas. Por sua vez, o tempo propício à manifestação da força desmedida era o cair da tarde, momento em que corpos cansados e descontrolados pelos efeitos do vinho, ou pelos medos nocturnos, agrediam amigos e inimigos. As agressões físicas atingiam diversas partes do corpo, sendo a cabeça o principal alvo, circunstância geradora de mortes que ocorriam, muitas vezes, na sequência de ferimentos mal curados devido às deficiências da medicina do tempo.

Os comportamentos agressivos dos homens do mundo rural decorrem, com frequência, do conflito de interesses em contextos de recursos escassos, sendo motivados pela competição no uso da água, da terra ou das áreas de

39 O tratamento das cartas de perdão da parte e régias referentes a Óbidos, no período de 1595-1680, evidenciou um conjunto de crimes classificados da seguinte forma: 52\% de ofensas corporais, $23 \%$ homicídios, $9 \%$ fuga de presos, $8 \%$ desfloração, $2 \%$ adultério e $2 \%$ resistência à autoridade (Dina Catarina Alves, Violência eperdão em Óbidos (1595-1680), dissertação de mestrado, Faculdade de Letras/Universidade de Coimbra, 2003). Por sua vez, nas escrituras de perdão da parte celebradas em Vila Nova de Gaia nos séculos XVII e XVIII, em 84,7\% dos casos perdoaram-se agressões, em 9,9\% crimes contra honra e virgindade e em 1,6\% crimes contra a propriedade (Isilda Braga da Costa Monteiro, «A litigiosidade e o « perdão» em Vila Nova de Gaia (séculos XVII e XVIII), Revista de ciências históricas, vol. XI, Universidade Portucalense, Porto, p. 106). Nos 134 perdões régios concedidos a estudantes no período que decorreu entre 1581 e 1638 foi apurada a seguinte distribuição: $38 \%$ de crimes contra a vida e integridade humana, 33\% contra a administração da justiça, contra interesses da coroa, liberdades pessoais, ordem pública, moral sexual vigente, património, religião (BRAGA; Paulo Drumond, Coimbra e a delinquência estudantil (1580-1640), Lisboa, Hugin Editores, 2003, p. 38). Sobre violência estudantil cf. António de Oliveira "O quotidiano da Academia", in História da Universidade em Portugal, vol. I, tomo II (1537-1771), pp. 679-682.

40 Robert Muchembled, $L$ 'invention de l'homme moderne. Sensibilités, moeurs et comportements collectifs sous l'Ancien Régime, Paris, Fayard, 1988; Norbert Elias, O processo civilizacional. Lisboa, Dom Quixote, 1989, 2 vols. 
pastagem (sobretudo comunitárias) ou pela necessidade de bens alimentares em tempos de carência, circunstância geradora de furtos, reprimida, de forma especial no século XVII ${ }^{41}$.

A expressão da força que ultrapasse os limites da ordem, tomando-se violência criminalizavel, foi protagonizada muitas vezes por homens que se faziam acompanhar de armas, que utilizavam no exercício da sua profissão ou para se defenderem de inimigos imprevisíveis e animais perigosos (lobos), transmutando-se, amiudadas vezes, esses instrumentos de defesa em objectos de agressão ${ }^{42}$. Tão potencialmente perigosas como as armas de fogo eram as pedradas lançadas por homens adestrados no seu manejo como eram os pastores ${ }^{43}$. A tentativa de dissuasão deste comportamento, responsável por muitos homicídios, levou o Estado a aplicar-lhe uma forte penalização: em 1659 foi atribuída a pena de açoutes e degredo aos maiores de 15 anos que jogassem pedradas ${ }^{44} .0$ controlo do uso indevido de armas de fogo foi igualmente objecto de particular controlo sobretudo no século XVII.

41 Ao longo do século XVII, vários diplomas, contendo normas ou dispositivos legais destinados a garantir a segurança de bens e pessoas, invocam a existência de roubos em espaços rurais e urbanos, em especial em Lisboa. Um diploma datado de 18 de Dezembro de 1617 dava conta de "muitos furtos" cometidos por ladrões, situação que obrigava os oficiais da justiça a correrem a cidade de dia e de noite (Collecção Chronologica da Legislação Portuguesa, 1613-1620, p. 167). Por sua vez, em 1630, a câmara de Lisboa invocando a existência de «tumultos, mortes e furtos» que todos os dias aconteciam na cidade, solicitava ao monarca o provimento de juízes do crime (OLIVEIRA, Eduardo Freire de, Elementos para a História do Município de Lisboa, tomo III, Ia parte, 1888, p. 387). A situação de insegurança urbana agravou-se nos inícios da guerra da Restauração. Em 1643, o monarca tendo sido informado de que andavam de noite, "com grande desvario e ousadia, muitos ladrões fazendo varios roubos, e outros insultos muito prejudiciaes" ordena às justiças que actuem no sentido de repor a ordem pública (Collecção Chronologica da Legislação Portuguesa, 1640-1647, pp. 237-238). A negligência dos "ministros criminais" em matéria de delitos que se cometiam na cidade de Lisboa consta de outro diploma datado de 27 de Novembro de 1662 (Collecção Chronologica da Legislação Portuguesa, 1657-1674, p. 80). Sobre a violência nas ruas de Lisboa vide BRANCO, Femando Castelo, Lisboa Seiscentista, Lisboa, Livros Horizonte, 1990, pp. 127-152.

42 Sobre os instrumentos utilizados nas agressões ver: RAMOS, Anabela, Violência e Justiça.., pp. 52-56; ALVES, Dina, Violência eperdão... pp. 121-123.

43 Num motim organizado na Madeira, contra um magistrado encarregado da execução de dívidas fiscais a mercadores, participaram "duas mangas de gente armada e com sevadeiros de pedras e frendas". O cabeça de motim viria a receber perdão régio em 20 de Setembro de 1640. Cf. Aires dos Passos Vieira, "Subsídios para a história da criminalidade da Madeira nas épocas de Filipe II e III", pp. 491-492; Por sua vez, em 16 de Janeiro de 1710, os pescadores da Ribeira de Lisboa tinham preparado cestos de pedras que atiraram a soldados que pretendiam tirar peixe dos barcos (Luís Ferrand de Almeida, "Motins populares no tempo de D. João V. Breves notas e alguns documentos", separata da Revista de História das Ideias, volume 6, Coimbra, 1984, p. 341).

44 Collecção Chronologica da Legislação Portuguesa, vol 1657-1674, p. 72. 
Os comportamentos violentos constituíam, entretanto, um fenómeno transversal aos vários grupos sociais: fidalgos, estudantes, magistrados régios, membros do clero, mercadores, soldados, homens e mulheres de diversas condições sociais $^{45}$. As mulheres foram apanhadas pela justiça acusadas sobretudo de violência verbal, sendo igualmente capazes de praticar actos de particular violência física, como homicídios dos maridos ${ }^{46}$, ou de empunharem armas para se defenderem de agressões ${ }^{47}$.

\section{Expressões de violência colectiva}

O tempo da construção do Estado Moderno foi marcado por profundos conflitos sociais e políticos expressos em manifestações de violência colectiva no contexto de revoluções e revoltas, rurais e urbanas. As pesquisas sobre movimentos sociais prosseguidas em França permitiram a elaboração de uma tipología que agrupa as "emoções populares" nas categorias seguintes: rejeição das iniciativas reformadoras do Estado; resistência à fiscalidade ou para-fiscalidade estatal; resistência ao aparelho judiciário, militar ou policial do estado; actos de hostilidade aos senhorios ou aos seus agentes; actos de hostilidade em relação à nobreza e aos seus privilégios; actos de hostilidade em relação à igreja; contestação de notáveis e/ou de simples habitantes; contestação da autoridade municipal; subsistências; religião; crenças; conflitos de trabalho; particularismo regional; diversos.

Estas acções violentas, decorrentes da "consciência de uma privação, de uma agressão ou de uma ameaça, efectiva ou imaginária", eram dirigidas "contra indivíduos revestidos de autoridade monárquica, senhorial, municipal, nobiliárquica ou eclesiástica; contra pessoas que pelas suas funções, fortuna, actividades ou pretensões afrontavam outros membros da colectividade, ou contra indivíduos ou grupos que cristalizavam a hostilidade colectiva por motivos étnicos, religiosos ou culturais" 48 .

45 Um quadro dos comportamentos violentos dos homens seiscentistas foi traçado por MAGALHÃES, Joaquim Romero in História de Portugal, Lisboa, Círculo de Leitores, 1993, vol. III, pp. 575-581.

46 RIBEIRO, Ana Isabel, "Um crime conjugal no feminino: o caso Clesse (1771-1772)", Sep. de Rev. Portuguesa de História, t. 35 (2001-2002); FARGE, Arlette, DAUPHIN, Cécile, (dir.), De la violence et des femmes, Paris, Albin Michel, 2000.

47 "Uma mulher nas malhas da justiça senhorial na Gándara do século XVII", Revista Portuguesa de Historia, t. 36, Coimbra, 1996.

48 Mouvements populaires et conscience sociale (XVI-XDC siècles). Actes du colloque de Paris, Paris, 1985, pp. 761-763; Nicolas, Jean, La Rébellion Française. Mouvements populaires et Conscience Sociale 1661-1789, Paris, Seuil, 2002. 
Esta tipología é suficientemente abrangente para englobar as diversas formas de protesto ocorridas em Portugal nos séculos XVII e XVIII, não nos sendo ainda possível aferir, com rigor, do grau de aplicabilidade à realidade portuguesa devido à inexistência de um levantamento sistemático de motins e levantamentos. As investigações mais profundas na área dos movimentos sociais no nosso país devem-se a António de Oliveira, que estudou, de forma exaustiva, e teorizou com perspicácia, a contestação antifiscal nas décadas finais do domínio filipino ${ }^{49}$ e a José Manuel Tengarrinha que inventariou os movimentos populares agrários, no período que decorre entre 1751 e $1825,{ }^{50}$ entre eles os cariz anti-senhorial e os que tiveram origem em apropriações abusivas de propriedade comunitária ${ }^{51}$.

"As acções colectivas violentas, pela sua frequência, eram familiares tanto aos camponeses como aos urbanos" (António de Oliveira) do século XVII e também do século XVIII, ainda que, eventualmente, com grau de intensidade menor. Este facto expressa-se na historiografia modernista portuguesa através de vários estudos que nos revelam acções violentas em espaços urbanos e rurais exercidas sobre pessoas, bens ou símbolos do poder ${ }^{52}$. Entre eles permitimo-nos destacar o "estado da arte" em matéria de "movimentos de contestação e protesto", bem como as sábias sugestões de natureza metodológica apresentadas por Luís Ferrand de Almeida, em 1985, no artigo "Motins populares no tempo de D. João V"53.

Ateorização sobre movimentos sociais e, em particular, sobre violência colectiva tem registado um grande desenvolvimento nas últimas décadas, não cabendo a sua apresentação no contexto deste artigo. Permitimo-nos, entretanto, invocar aqui algumas apreciações dos contemporâneos sobre os movimentos de protesto. D. Francisco Manuel de Melo, reportando-se às revoltas de Évora de 1637,

\footnotetext{
49 OLIVEIRA, António, Movimentos sociais epoder em Portugal no século XVII, Coimbra, IHES, 2002.

50 TENGARRINHA, José M, Movimentos populares agrários em Portugal, I (1751-1807), II (1808-1825), Lisboa, Publicações Europa-América, 1994.

51 Para a região de Coimbra ver: NETO, Margarida Sobral, "Motins Populares na Gándara em 1778", in Actas do Congresso "Maria da Fonte -150 anos". 1846/1996, Câmara Municipal da Póvoa de Lanhoso, 1996, pp. 185-194; Idem, Terra e Conflito. Região de Coimbra (1700-1834), Palimage Editores, Viseu, 1997.

52 Capela, José V, "Tensões Sociais na Região de Entre-Douro e Minho", O Distrito de Braga, volume III da 2a série (VII), 1978; SILVA, Francisco Ribeiro, Absolutismo esclarecido e intervenção popular: os motins do Porto de 1757, Lisboa, INCM, 1990; RIBEIRO, Ana Isabel, Um conflito entre poderes na Gándara da Bunhosa no início do século XVII, sep. de: Rev. Portuguesa de História, t. 32 (1997-1998).

${ }^{53}$ ALMEIDA, Luís Ferrand de, "Motins populares no tempo de D. João V. Breves notas e alguns documentos", separata da Revista de História das Ideias, volume 6, Coimbra, 1984.
} 
chamou a atenção para a "indústria dos oprimidos", que devia servir de exemplo ao poder no sentido "de remediar a opressão dos vassalos, antes que eles se disponham ao remédio dela" 54 . Por sua vez, Azeredo Coutinho escreveu em 1748: “...He certo que os motins e tumultos ordinariamente nascem da desesperação e da violência e o amor da liberdade então se accende mais quando se experimenta mais onerosa a escravidão"55.

O sentimento de injustiça congregou as populações em movimentos de protesto dirigidos sobretudo contra oficiais de justiça (juízes de fora, corregedores ou ouvidores), bem como contra agentes senhoriais (juízes executores) ou contratadores de rendas, que perseguiram e por vezes agrediram até à morte. Os responsáveis pela opressão dos povos viram ainda, com frequência os bens destruídos e as casas incendiadas. Alvos de destruição pelo fogo foram ainda os edifícios onde se guardavam os papéis dos impostos ou processos judiciais.

Uma das agressões mais sentidas pelas comunidades era a vedação de terras comunitárias ou de espaços abertos a usos comunitários. Por este motivo a convocação do povo para derrube de muros tinha um poderosíssimo efeito mobilizador. O recrutamento de homens para a guerra era outra situação que congregava ânimos e solidariedades que se dispunham a resistir à operação de "fazer soldados". José Tengarrinha cita, entre outros, o diploma de 20 de Dezembro de 1784 que dá conta de insultos e resistências às autoridades militares a quem chegavam a tirar "violentamente" os recrutas ${ }^{56}$.

Finalmente, a falta de pão combinada, por regra, com preços elevados e suspeitas, reais ou imaginadas, de aproveitamentos por parte dos atravessadores, deu origem a protestos vários, que contavam sempre com a activa participação das mães de família.

As manifestações de protesto podiam configurar vários tipos de crime, assuada, resistência à autoridade, ofensas à justiça, ou mesmo lesa-majestade, todos eles susceptíveis de punição severa da parte das autoridades. $O$ castigo exemplar recaía, sobre os cabeças de motim, muitas vezes em número de seis, que expiavam os "crimes" de desobediência cometidos por comunidades inteiras. Em momentos de maior intensidade de protesto a identificação destes homens implicava a prévia pacificação das gentes revoltadas. Em 1811, na Gándara, (região de Coimbra) os ânimos só serenaram perante uma força militar de trezentos homens ${ }^{57}$.

\footnotetext{
${ }^{54}$ Citações de António de Oliveira, Movimentos sociais..p. 31.

" Citação de Luís Ferrand de Almeida, "Motins populares...", p. 338.

56 Movimentos populares agrários, vol. I, p. 171.

57 NETO, Margarida Sobral, Terra e conflito..., p. 348.
} 


\section{A violência dos poderes}

A cultura de violência característica do Antigo Regime, e de forma particular do século XVII, não se evidencia apenas no sangue que corre no seio das comunidades resultante de relações interpessoais violentas, ela é também, ou talvez sobretudo, protagonizada pelos poderes no exercício da sua actividade de pacificação social e de imposição de normas de conduta e de valores sociais e ideológicos ${ }^{58}$, sendo bem expressa na violência da punição. Com efeito, as molduras penais definidas para os crimes, consignadas nas Ordenações, bem como em outra legislação penal publicada ao longo da Idade Moderna, são uma prova da apropriação por parte do Estado da "violência legal"59. Uma das primeiras expressões deste facto manifesta-se na circunstância de a reforma manuelina dos forais ter retirado dos textos da Idade Média a regulamentação em matéria criminal, extinguindo a diversidade de molduras penais existente no país, e impondo um sistema integrado de penas consignado nas Ordenações Manuelinas, transposto, posteriormente, como demonstra Eduardo Correia para as Ordenações Filipinas ${ }^{60}$. Nestes códigos jurídicos vemos prodigalizadas com abundância diversos tipos de penas: de morte (por enforcamento, degolamento ou pelo fogo, sendo precedidas em alguns casos de torturas), corporais (de mutilação e tortura); infamantes (baraço e pregão), de prisão no tronco, em cadeias ou no domicílio, de galés e de degredo, que nos crimes mais leves se cumpria no território continental, fora do lugar de residência ou em Castro Marim, e nos mais graves em África, índia ou no Brasil. A acrescentar a este penoso cortejo existiam as pecuniárias, originalmente impostas ou resultantes de comutação de penas em tempos de aperto financeiro.

58 Sobre as formas de "disciplinamento social" ver: Furor et rabies: violencia, conflicto $y$ marginación en la Edad Moderna, ed. José I. Fortea, Juan E. Gelabert, Tomás A. Mantecón, Santander, Serv. de Publicaciones de la Univ. de Cantabria, 2002.

59 Sobre o directo penal utilizado como instrumento do poder centralizador ver: TOMÁS Y VALIENTE, Francisco, El derecho Penal de la Monarquia Absoluta (siglos XVI, XVII, XVIII). Madrid, Editorial, Tecnos, 1969, (2aed. 1992); TOMÁS Y VALIENTE, Francisco, El derecho Penal como instrumento de Gobierno. "ESTUDIS", 22, pp. 249-262; MUCHEMBLED, Robert, Le Temps Des Supplices. De l'obéissance sous les Rois Absolus. XVe-XVIlIe Siècle, Paris, Armand Colin, 1992; HERAS SANTOS, José Luís, La justicia penal de los Austrias en la corona de Castilla, Salamanca, 1994.

60 Eduardo Correia, Estudo sobre a evolução das penas no direito português, "Boletim da Faculdade de Direito", Universidade de Coimbra, 1977, (53), pp. 51-310; Francisco Freire de Melo, Discurso sobre os delictos e as penas e qual foi a sua proporção nas diferentes épocas da nossa jurisprudência, Londres, 1816; Francisco Ribeiro da Silva, "Marginais e marginados à luz das Ordenações Filipinas”, sep. de: Revista de Ciências Históricas, vol. 11,1996, pp. 69-76. 
António Hespanha invocando a falta, por parte da monarquia, de meios institucionais e humanos, de domínio efectivo do território e do próprio aparelho de justiça, "expropriado ou pelo comunitarismo das justiças populares ou pelo "corporativismo" dos juristas letrados", defende que o sistema penal da monarquia corporativa teve como principal função afirmar "o sumo Poder do rei como dispensador, tanto da justiça como da graça"61. Esta tese é comprovada através da informação disponível sobre aplicação da pena de morte, nomeadamente na existente numa relação dos presos da cadeia de Lisboa entre 1694 e 1696 ou na disponibilizada pela listagem das condenações à pena capital elaborada por Henriques $\mathrm{Seco}^{62}$, informações que permitem concluir que a pena de morte foi muito pouco aplicada durante o Antigo Regime ${ }^{63}$. Para o mesmo autor "o segredo da específica eficácia do sistema penal do Antigo Regime estava justamente nesta "inconsequência" de ameaçar sem cumprir. De se fazer temer ameaçando; de se fazer amar, não cumprindo"64.

Se a imagem do poder régio se construiu com perdões gerais e punições selectivas, construiu-se igualmente com punições exemplares e brutais como aquelas de que foram alvo, no reinado de D. José, os acusados de crime de lesa-majestade, como os Távoras ${ }^{65}$ ou os participantes nos motins do Porto, em 1757, contra a Companhia Geral da Agricultura das Vinhas do Alto Domo. Estes amotinados foram vítimas de uma "duríssima e desproporcionada repressão" (Ferrand de Almeida) susceptível de ser dissuasora de outros protestos populares: os considerados mais responsáveis (21 homens e 5 mulheres) foram "condenados a percorrer as ruas da cidade com baraço e pregão e a enforcamento, seguido de degolação e esquartejamento dos membros, confiscação de todos os bens e declaração de infame a sua memória, infâmia extensiva a filhos e netos". Por sua vez, a 15 rapazes por serem "impúberes", foram condenados "a assistir às execuções e a dar 3 voltas à roda das forcas e a uma dúzia de palmatoadas"66.

61 HESPANHA, António, “A punição e a graça”, in MATOSO, José (dir), História de Portugal, Lisboa, Círculo de Leitores, 199, p. 239.

62 SECO, António Luiz de Sousa Henriques Secco, Memórias do tempo passado e presente para lição dos vindouros, Coimbra, 1880.

63 HESPANHA, António, "A punição e a graça", ob.cit., p. 243; OLIVEIRA, António Braz, As execuções capitais em Portugal num curioso manuscrito de 1843. "Revista da Biblioteca Nacional de Lisboa”, vol. 2, (1), Jan-Jun, 1982, pp. 109-127.

64 HESPANHA, António, “A punição e a graça”, ob.cit., p. 244.

65 GOMES, Manuel João (coord.), O processo dos Távoras - a expulsão dos jesuítas, Lisboa, Edições Afrodite, 1974.

66 Sobre outras penas (açoites, galés, degredo e confiscação de bens) ver o valioso estudo de SILVA, Francisco Ribeiro da, Absolutismo Esclarecido e Intervenção Popular. Os motins do Porto de 1757, Lisboa, 1990. 
Nas sociedades de Antigo Regime "o poder oscila entre oscila entre a vida e a morte, a graça e a repressão", fazendo "a repressão parte da definição do poder e do seu impacto sobre a opinião pública" (Claude Gauvard) ${ }^{67}$.

$\mathrm{O}$ estado moderno respondeu às violências e transgressões dos súbditos com punições excessivamente violentas que atingiram todos os grupos sociais, incidindo, no entanto, com particular rigor sobre os homens e mulheres perigosos, entre os quais se destacam os vadios, os ciganos, os autores de crimes de lesa-majestade, os profanadores de espaços sagrados e os judeus.

A punição de comportamentos que faziam parte da "integridade moral" ou das "representações simbólicas" da comunidade de vassalos do monarca e de fiéis da Igreja, constitui uma das faces mais brutais da violência da Idade Moderna. Com efeito, o Estado e a Inquisição castigaram actos violentos (ofensas corporais, violações, homicídios) e não violentos (comportamentos sexuais, crenças religiosas, formas de cultura popular) com punições brutais: pena de morte, natural ou civil, autos de fé, galés, degredos, prisões, açoites no tronco, exposição de cadáveres, por vezes mutilados, suspensos nas forcas ${ }^{68}$.

A eficácia da crueldade das penas infligidas sobre o corpo dos criminosos foi posta em questão pelos pensadores iluministas, nomeadamente por Cesare Beccaria na afirmação seguinte: "um dos maiores freios dos delitos não é a crueldade das penas, mas a sua infalibilidade, e por consequência a vigilância dos magistrados, e a severidade de um juiz inexorável..."69. Em sintonia com este pensamento, em Portugal, na segunda metade do século XVIII, foram tomadas medidas tendentes ao aperfeiçoamento de um aparelho judiciário que procurou monopolizar o exercício da justiça, sobrepondo-se às instâncias infra-judiciárias da resolução de conflitos e punição de transgressões e às vinganças privadas ${ }^{70}$.

${ }^{67}$ GARNOT, Benoit (dir), Ordre Morale et Délinquance de l 'Antiquité au XXe Siècle, Dijon, 1994, pp. 499-500.

68 COELHO, Antonio Borges, Inquisição de Évora: dos primórdios a 1668, Lisboa, Caminho, 1987,2 vols; COATES, Timothy J., "crime and punishement in thr fifteenth-century portuguese world: the transition from internai to imperial exile", in KAGAY, Donald J., VILLALLON, L. J. Andrew, The final argument: the imprint of violence on society in medieval and early modem Europe, Woodbridge, Sufifolk, The Boydell Press, 1998; Ana Cristina Araújo, "Cerimónias de execução pública» no Antigo Regime - escatologia e justiça", Revista do Centro de História da Sociedade e da Cultura, ${ }^{\circ} 1$, Coimbra, 2001, pp. 169-211.

${ }^{69}$ BECCARIA, Cesare, Dos delitos e das penas, Lisboa, Fundação Calouste Gulbenkian, Serviço de Educação, 1998, p. 115; VOLTAIRE, Tratado sobre a tolerância, Lisboa, Antigona, 1999.

70 Antonio Manuel Hespanha, «Da «Justitia» á «Disciplina», Textos, poder e política penal no Antigo Regime» in Justiça e litigiosidade: Historia eprospectiva. Lisboa: Fundação Calouste Gulbenkian, 1993, pp. 287-320; HESPANHA, Antonio, "Sábios e rústicos: a violência doce da razão jurídica”, Revista Crítica de Ciências Sociais: o Poder local, 25/26. Coimbra, 1988, p. 31-60. 
Ao mesmo tempo, o Estado dotou-se de mecanismos mais eficazes de controlo e repressão social tendentes a impor modelos de comportamento civilizados e a extinguir "costumes bárbaros". À Intendência Geral da Polícia, organismo criado em 1760, foi atribuído o papel de controlo da violência social ${ }^{71}$, nomeadamente a praticada por perigosos vagabundos, a desenvolvida no contexto das lutas entre aldeias, ou os rituais e espectáculos violentos, caso das corridas de touros ${ }^{72}$.

Os estudos já realizados permitem concluir que os homens na Idade Moderna se foram tomando progressivamente menos violentos, facto que se expressa por exemplo na diminuição das taxas de homicídio, na Europa, a partir de $1750^{73}$. $\mathrm{Na}$ segunda metade do século XVIII, assiste-se, no entanto, a uma mudança nos tipos de delinquência. Com efeito, as estatísticas evidenciam um recuo da criminalidade violenta contra pessoas e um crescimento da delinquência anti-propriedade ${ }^{74}$. Não temos, em Portugal, estudos que nos permitam comprovar estas tendências, mas dispomos de alguns indicadores. De um estudo elaborado por Maria Antonia Lopes referente a delitos praticados pelos presos da cadeia da Portagem (Coimbra), no período de 1768-1779, conclui-se que os principais crimes que levavam os homens e as mulheres ao cárcere eram de natureza económica, numa percentagem de $26,60 \%$ em relação aos primeiros e de $47,17 \%$ às segundas. Em segundo lugar vêm os crimes do foro militar praticados pelos homens $(17,55)$ e as ofensas contra a moral pública $(22,64 \%)$ de autoria das mulheres.

Já os crimes em relação às pessoas assumem valores muito inferiores relativamente aos anteriormente apontados, cabendo aos homens $13,30 \%$ e às mulheres $7,55 \%$. Para o mesmo período a detenção mais longa (2 anos) reportava-se a

71 Sobre este assunto ver CRESPO, Jorge, A História do Corpo, Lisboa, Difel, 1990, pp. 275-30; NORONHA, Eduardo de, Pina Manique, costumes, banditismo e polícia no Jim do século XVIII, princípios do século XIX 1 Porto, Liv. Civilização, 2a ed., 1940; SUBTIL, José, Forças de segurança e modos de repressão (1760-1823), in Costa, Femandes Marques e outros, "Do Antigo Regime ao Liberalismo", Lisboa, Veja, 1989.

72 "Os Combates de Touros sempre forão considerados como hum divertimento improprio de huma Nação civilizada. Espectáculos desta natureza são quase sempre acompanhados de desastres, ou no lugar do mesmo espectáculo, ou na condução dos animaes: e estas scenas de sangue somente são capazes de inspirar ao povo grosseiro inclinação aos assassínios" (ANTT, Intendência Geral da Polícia, citado por CRESPO, Jorge, A História do Corpo, Lisboa, Difel, 1990, p. 285).

73 ROUSSEAU, Xavier, "Ordre morale, justices et violence: l'homicide dans les sociétés européennes. XIIIe-XVIII siècle », in GARNOT, Benoit (dir), Ordre Morale et Délinquance de VAntiquité au XXe Siècle, Dijon, 1994, pp. 65-82.

${ }^{74}$ LADURIE, Emmanuel Le Roy, «Violence, délinquance, contestation », in DUBY, Georges, WALLON, Armand (dir.), Histoire de la France Rurale, Paris, Seuil, 1975, vol. 2, pp. 547-575. 
um crime de invasão de propriedade alheia, seguindo-se outra, de um ano, aplicada a um autor de homicídio ${ }^{75}$. Do atrás exposto se conclui que a ofensiva do "jus punendi" se dirigia no sentido da construção do conceito de propriedade que viria a implantar-se com a Revolução Liberal.

\section{Um tempo violento que ainda não perdemos}

Do atrás exposto decorre que o estudo da violência na Idade Moderna, atendendo ao tipo de fontes utilizado (legislativas, normativas, judiciais, registos de prisões), tem sido sobretudo o estudo do controlo das acções violentas e das práticas culturais que o Estado e a Igreja criminalizaram no contexto da construção da unidade religiosa e política. Os resultados da investigação nesta área temática não se têm, por este motivo, limitado ao conhecimento de protagonistas de violências ilegítimas e legítimas. Com efeito, a violência na Idade Moderna constitui-se como um observatório privilegiado de estudo das relações sociais, dos sistemas de poder e da construção de valores e sentimentos que perduram no nosso tempo. Estudar e tentar compreender a violência na Idade Moderna não significa apenas conhecer os Outros, mas projectar alguma luz sobre "a face mais obscura de nós mesmos" (Muchembled). 